\title{
Cautionary tale on safety of GM crops
}

Sir - I am very much in favour of Nature's use of Scientific Correspondence to bring to our attention potentially important research before full publication of results. But there is a need for scientific rigour in the presentation of the information to ensure that it is not misrepresented. The report by Losey et al. in Scientific

Correspondence is a preliminary research finding offering insight into the topical and important issue of genetically modified (GM) crops (Nature 399, 214; 1999). It has alerted the UK Advisory Committee on Releases to the Environment (of which I am chairman) to a potential problem that will require very serious thought.

It has also been assumed to demonstrate that GM crops harm butterflies and has fuelled public anxiety about such crops. The report is highly indicative of harm caused by pollen from the maize plants used in this particular study, but the work is at this stage preliminary rather than definitive. It is clearly stated in the text, for example, that pollen for the non- $B t$ (Bacillus thuringiensis) maize control was from an unrelated, untransformed hybrid. However, there is no reported control to demonstrate that pollen from the transformed variety was not toxic in the absence of the functional Btgene.

Losey et al. refer to a study (their ref. 3) stating that maize pollen is dispersed over at least 60 metres, and comment that a substantial portion of available milkweed (eaten by monarch butterflies) may be within the range of corn pollen distribution. But Losey et al. do not report a dilution study, so there is no evidence that dilute pollen would have an impact on larvae. Of course it is desirable to point out the potential harm that may arise from pollen dispersal, which in this case could be very important, but the data reported by Losey et al. do not directly pertain to this issue.

On 20 May I stated on the BBC Radio Today programme that the letter by Losey et al. was not peer reviewed and that the work might be flawed. I am now aware that it was peer reviewed (as are all contributions to Scientific Correspondence), and wish to apologize. My suggestion that the work might be flawed was not intended as a slight but was a reminder to the press that preliminary observations should not be overinterpreted. Regrettably, most reporting of the communication has almost entirely ignored the need for such caution. John E. Beringer

School of Biological Science, University of Bristol, Woodland Road, Bristol BS8 1UG, UK

\section{PlantDNA patents in}

\section{the hands of a few}

Sir - Consolidation in the agrochemical and seed industry continues to shorten the list of owners of 'enabling' intellectual property for plant genetic modification and molecular biology. Six major groups of multinational companies are poised to develop and patent agronomically important plant genes identified in genome sequencing programmes for crop improvement (see page 396 in this issue and ref. 1). The ensuing cascade of patenting will have important implications for technology access and global food security. We report below on the ownership of patent applications with claims for DNA sequences from the world's major crops.

The finding that most patent applications have been filed by industry suggests that a strong advocate for the developing world will be needed to establish partnerships between industry and public laboratories to ensure that the benefits of genetic-modification technology will be widely available. This should be broadly achievable within the current patent regime, but we urge patent holders to be aware of their wider responsibilities when considering licensing terms.

We analysed patent applications with a filing date between 1980 and 1996 that make claims to DNA sequences (GENESEQ and World Patent Index databases, Derwent Ltd). The search, limited to 78 plant species of economic or scientific importance, revealed 601 patent applications containing one or more DNA sequences from 60 species. About half have been granted.

About three-quarters of the applications were filed by 115 companies. Half of this total (48\%) were filed by 14 multinationals. Recent corporate acquisitions by Monsanto have resulted in the company having the largest stake, with 69 applications, followed by Zeneca and Novartis.

Twenty-eight per cent of applications were filed by public-sector institutions. Over half of these are US owned. Four US universities and the US Department of Agriculture are in the top ten public institutions. In Europe, it is research institutes rather than universities that have sought to protect their inventions. Although the UK John Innes Institute and Germany's Max Planck and Institut für Genbiologische Forschung institutes have together filed half of the European public-sector total, Europe's stake is relatively low at a quarter of the world public-sector share. Public and private US organizations have $43 \%$ of the total, compared to 25\% for Europe and 19\% for Japan.

Maize was the most heavily patented species, claimed in almost $10 \%$ of the total, closely followed by the model plant Arabidopsis. About $40 \%$ of the patent applications included claims for cereals and pulses, one-third included fruit and vegetables, while claims to oilseed and model plants occurred in about one-quarter. Species used for fibres, beverages, herbs and spices accounted for the rest (10\%). The overall total exceeds $100 \%$ because some applications include more than one species. Patent applications were not confined to crop species grown in developed countries.

\begin{tabular}{ll}
\hline $\begin{array}{l}\text { Table } 1 \text { Predominant functions claimed for } \\
\text { plant genes in the 601 patents analysed }\end{array}$ \\
\hline Nutrition & 109 \\
\hdashline Pathogen resistance & 106 \\
\hdashline Regulatory DNA sequences & 97 \\
\hdashline Growth and morphology & 56 \\
\hdashline Sterility & 45 \\
\hdashline Herbicide tolerance & 36 \\
\hdashline Ex-plant production & 30 \\
\hdashline Antisense & 24 \\
\hdashline Plants as producers & 22 \\
\hline Environmental & 21 \\
\hdashline Colour & \\
\hline
\end{tabular}

Some patents are counted in more than one category. A further 69 patents covered fibres, diagnostics, mapping and miscellaneous categories.

DNA sequences from nutmeg, cinnamon, rubber, jojoba and cocoa have been claimed by inventors from developed countries.

The applications, which rarely claimed more than one sequence, were dominated by genes associated with nutrition $(20 \%)$, pathogen resistance $(20 \%)$ and gene regulation (18\%) (Table 1). Those in nutrition included genes that determine the amount or type of sugar, starch, oil or protein in the plant, encode enriched proteins, and reduce the level of allogenic proteins in rice. Genes that contribute to pathogen resistance encode a wide variety of enzymes including chitinases. Regulatory DNA sequences in the form of

transcriptional promoters are claimed that are in general tissue-specific. The gene sequences regulated by these promoters are also claimed in some cases.

Plant development and reproduction are of central importance to plant breeders, and $10 \%$ of applications fell within this class. Several concern modification of ethylene 
production and the extent and pattern of flowering. Genes that confer male sterility are of particular value to the breeder, and account for about $8 \%$ of applications.

Although much of the controversy surrounding genetically modified crops concerns herbicide tolerance, only $7 \%$ of applications relate directly to this trait. These include genes encoding glutathione $S$-transferase IIIc, acetolactate synthase, lycopene cyclase and a protein conferring glyphosate resistance. The complexity of gene function is well illustrated by the acetyl-CoA carboxylase gene, which confers herbicide tolerance in monocotyledons but is claimed primarily for regulating oil content.

S. M. Thomas ${ }^{\star} \uparrow$, M. Brady $\dagger$, J. F. Burke $\ddagger$

${ }^{*}$ Nuffield Council on Bioethics,

28 Bedford Square, London WC1 3EG, UK

$\dagger$ Science Policy Research Unit and

$\ddagger$ Department of Biochemistry,

University of Sussex, Brighton BN1 9QG, UK

1. Nuffield Council on Bioethics Genetically Modified Crops: Ethical and Social Issues (NCOB, London, 1999).

\section{Papers should spell} out authors' roles

Sir - When scientific papers with multiple authors are published, an indication should be given of the contribution that each author has made to the research. Nature recently published a paper by more than 20 authors. We can only guess what the contribution of author No.17 might have been, but it might be important to let the reader know about that, not least for the benefit of author No.17 himself. We propose the following system, which would take up minimal space in the journal.

All authors should be listed again at the end of the paper with a short statement about their contributions (Table 1). No matter if the author is the first or the seventeenth, they will be able to show their part in the work, which might be helpful for their future careers, especially in the case of younger scientists ${ }^{1}$. This system will be informative for readers and also for potential employers, who need to assess the work of scientists they might employ.

This statement of authorship would also strengthen scientific teams, because it would become more difficult for someone to usurp rewards not belonging to $\mathrm{him}^{2}$. Possible resentment about positioning

\begin{tabular}{ll}
\hline Table 1 Personal contributions to papers \\
\hline Author $\mathbf{1}$ & $\begin{array}{l}\text { Head of project, project design, } \\
\text { coordination, initial idea }\end{array}$ \\
\cline { 1 - 2 } $\mathbf{2}$ & General realization \\
\hline Author $\mathbf{3}$ & Reviewing \\
\hdashline Author $\mathbf{4}$ & Immunohistochemistry \\
\hdashline Author $\mathbf{5}$ & Electron microscopy \\
\hline
\end{tabular}

within the list of authors would be reduced, because each author would be given full credit according to their personal contribution. The scientific community would benefit - better research would emerge from teams that cooperated rather than behaving like packs of wolves. And other scientists would find it easier to contact the right person to ask about a specialized area of the research.

\section{A. Zyzik, T. Goldmann}

Research Center Borstel, Parkallee 1-40,

D-23845 Borstel, Germany

Tarnow, E. Nature 398, 657 (1999).

2. Schiermeier, Q. Nature 397, 640-641 (1999).

\section{Scientists must bridge} the communication gap

Sir - Lewis Wolpert is characteristically thought-provoking in his Commentary "Is science dangerous?" . But he misses the point.

Wolpert informs us that scientists have "specialized knowledge of how the world works that is not easily accessible to others". In fact, scientists show us an aspect of how the world can be considered to work. This is related to a particular way of thinking that has sufficient common principles to allow for a community of thought and discussion. The great power of this method is its predictive capacity and its potential for application in everything from space rockets to genetically modified crops.

But the scientific method does not, as Wolpert believes, "tell us how the world is". What gives scientists their special voice and power is not the 'truth' of their theories, but the application of these theories in technology.

Power is dangerous and therefore so, potentially, is science. Not because, as Wolpert scornfully suggests, our stupid culture is afraid of knowledge, but because scientists do not seem to be able to understand non-scientists. The understanding of scientists is limited to their particular approach to life. Or, to parody Wolpert, non-scientists have unspecialized knowledge of how the world works that is not available to scientists. Often the attempts of scientists to communicate to non-scientists only reinforce the divide: those who are interested in science enjoy the popularization; those who are not, do not.

Science, therefore, is dangerous because it is out of contact with much of its user base and, from some perspectives, is close to a tyranny. For too long scientists have patronized the non-scientific majority, and carried on with little concern for their reservations. The high-handed "It is essential to recognize" of Wolpert's article belongs in the past. Scientists are boxing themselves into a corner by their inability to see that other people have a legitimate right not to see the world scientifically, and by their poor social skills. In science it is a virtue to be somewhere between forceful, condescending and arrogant. When communicating science, it is a disaster.

From 'mad cow disease' to genetically modified food, scientists have been failing to convince. No longer able to understand the language and aspirations of their fellow humans, they are moving from the position of curious outgroup to vulnerable minority. Science is useful, and the world it reveals is amazing. But Wolpert and the rest of us must understand that scientists can no longer dictate to the world. It is essential to realize.

Nick Battey

School of Plant Sciences,

The University of Reading, Reading RG6 6AS, UK

Sir - Wolpert's Commentary ${ }^{1}$ seems quite naive. Take the key point of the supposedly 'neutral' knowledge provided by science. Wolpert says: "It is essential to recognize that reliable scientific knowledge has no moral or ethical value. Science tells us how the world is." From this, all the rest of the article's argument follows - we can't discuss reality, we can only accept it.

This crucial idea is in itself dangerous. It should be obvious that all knowledge has been acquired and is therefore a mix of 'reality' and our own way of understanding - the glasses with which we observe, and distort, reality. These 'glasses' include reductionism (see ref. 2 for simple examples in biology), and the necessity of building stable entities that can resist controversies ('black boxes'3,4) and rapidly circulate within scientific networks ${ }^{3}$.

To use a crude analogy, science summarizes reality as much as a football score sums up two hours of emotions, missed opportunities and referee's mistakes. Any fan knows that the score does not exhaust the game, it only allows us to build a league table. Similarly, science chooses to extract from reality those features that allow it to build theories, and this demands high technology and a specific social organization.

The knowledge provided by science stems from the way the world is, but also from the way science has chosen to deal with it. Science is interwoven with technology, and the argument that 'science is pure, only its (technological) applications can be bad' might not be convincing for much longer in these distrustful times.

\section{Pablo Jensen}

DPM-Bat 203, 69622 Villeurbanne Cedex, France

1. Wolpert, L. Nature 398, 281-282 (1999)

2. Lewontin, R. Biology as Ideology (Harper, New York, 1992).

3. Latour, B. Science in Action (Harvard Univ. Press, 1988).

4. Jensen, P. Am. J. Phys. (submitted). 